\title{
Application of FE Modelling of Machining Using DEFORMTM
}

Filip Tikal, Miroslav Zetek, Tomáš Kavalír

Regional Technological Institute, Faculty of Mechanical Engineering, University of West Bohemia. Univerzitni 8, 306 14 Plzen.Czech Republic.E-mail: ftikal@rti.zcu.cz, mzetek@rti.zcu.cz, kavalirt@rti.zcu.cz

DEFORMTM is a robust modelling software tool which uses the finite element method (FEM) for modelling technologies in $2 \mathrm{D}$ and, naturally, in $3 \mathrm{D}$. One of the processes, the modelling of which DEFORM ${ }^{\mathrm{TM}}$ supports, is slab milling.

For this purpose it uses an advanced FE model with various parameters, such as the fracture criterion. If their values are not chosen correctly, the desired results cannot be obtained.

A 3D simulation model was developed to explore the capabilities for entering data, calculating and evaluating temperature distribution within a workpiece during experimental milling carried out under real-world cutting conditions. The FEM model concerns the temperature on the rake face of an exchangeable cutting insert. The primary aspect which was monitored was the temperature field during chip formation.

Finally, the results of the simulation were compared with data from a machining experiment. The material used for the simulation and for the machining experiment was the ČSN 12050.1 / AISI 1045 steel.

Keywords: slab milling, computer simulation, FEM, DEFORMTM, experiments

\section{Acknowledgement}

The present contribution has been prepared under project LO1502 'Development of the Regional Technological Institute' under the auspices of the National Sustainability Programme I of the Ministry of Education of the Czech Republic aimed to support research, experimental development and innovation.

\section{References}

[1] COPPEL, R., ABEllan-NEBOT, J.V., Siller, H.R., RODRIGUEZ, C.A., GUEDEA, F. (2016). Adaptive control optimization in micro-milling of hardened steels evaluation of optimization approaches. In: International Journal of Advanced Manufacturing Technology, vol. 9-12, pp. 2219-2238. Springer-Verlag London Ltd, UK.

[2] KOLAR, P., SUliTKA, M., FOJTU゚, P., FALTA, J., ŠINDLER, J. (2015). Cutting force modelling with a combined influence of tool wear and tool geometry. In: Manufacturing Technology, Vol. 3, pp. 524-531. Univerzita J. E. Purkyne, Czech Rep.

[3] PETRU, J., SCHIFFNER, J., ZLAMAL, T., SADILEK, M., STANCEKOVA, D. (2015). Investigations of cutting tool wear while machining inconel 718. In: Manufacturing technology, vol. 3, pp. 396-403. Univerzita J. E. Purkyne, Czech Rep.

[4] ASTAKHOV, V. P. (2010). Geometry of Single-point Turning Tools and Drills. Springer-Verlag London Limited ISSN 1860-5168, ISBN 978-1-84996-052-6, e-ISBN 978-1-84996-053-3.

[5] SCIENTIFIC FORMING TECHNOLOGIES CORPORATION (2014). DEFORM V11.0.2 Documentation. In: DEFORM ${ }^{T M}$ v1 1.0.2. Scientific Forming Technologies Corporation, Columbus, Ohio. 